\title{
NOMADISMO Y ETNICIDAD. DE-COLONIZAR EL SEDENTARIO COMO LUGAR DE ENUNCIACIÓN
}

\section{Nomadism and ethnicity. Decolonization of the sedentary as a place of enunciation.}

Nomadismo e etnicidade. De-colonizar o sedentário como lugar de enunciaçao.

\section{Leticia Katzer ${ }^{1}$}

Recibido: 10 de septiembre de 2019. Corregido: 8 de febrero de 2020. Aprobado: 11 de marzo de 2020.

\section{Resumen}

Hay un supuesto naturalizado de que la sedentarización es un proceso evolutivo natural. En esta narrativa, el nomadismo se hace presente de manera espectral: nómada es una huella, una palabra presente que se insinúa apenas diferida como m̃movilidadòo f̂rashumanciaò pero nómada parece ser innombrable, secreto. De lo contrario, nosotros sostenemos que la sedentarización no sólo no es natural ni inevitable sino que en casos es producto de una relación de poder colonial, de una imposición forzada y violenta. A partir del registro etnográfico reunido entre los años 2004 y 2017 en el secano de Lavalle, provincia de Mendoza (Argentina) buscamos mostrar dinámicas nómades en diálogo con estudios y enfoques teóricos diversos sobre el nomadismo en otras partes del mundo. Para ello articulamos planteos de la filosofía nómade junto con los estudios antropológicos en un esfuerzo por abordar el nomadismo con todo su alcance y complejidad, en términos políticos, culturales y económicos.

${ }^{1}$ Doctora en Ciencias Naturales (Área Antropología Social) por la Universidad Nacional de La Plata. Profesora titular de Antropología Aplicada, Universidad del Aconcagua, e investigadora del Consejo Nacional de Investigaciones Científicas y Tecnológicas (CONICET). Líneas de investigación: etnografía colaborativa, epistemología, crítica biopolítica, deconstrucción y filosofía nómade. Correo electrónico: Ikatzer@mendozaconicet.gob.ar

Acta Sociológica núm. 80, SePtiembre-diciembre de 2019, pp. 121-151. 
Palabras claves: nomadismo, sedentarización,colonialidad, desierto, pensamiento nómade, etnicidad

\begin{abstract}
A generally adopted assumption exists, suggesting that sedentarization is a natural evolutionary process. In such literature, m̃omadismò appears in a spectral way: m̃omadicò is a footprint, an insinuated word, justs lightly different from m̃mobilityò or Ĩrashumanceò However, the term m̃omadicò seems to be unmentionable, secret. On the contrary, we support that sedentarization is not just unnatural or inevitable, but in some cases, it is the result of a colonial power relationship, of a forced and violent imposition.

On the basis of the ethnographic record gathered between 2004 and 2017 in the Lavalle desert in the province of Mendoza (Argentina), we try to show nomadic dynamics in connection with diverse studies and theoretical approaches on nomadism in other parts of the world. For that purpose, we articulate arguments of the nomadicphilosophy with anthropological studies, in an effort to approach nomadism in its whole scope and complexity, from the political, cultural and economic points of view.
\end{abstract}

Key words: nomadism, sedentarization, coloniality, desert, nomadic philosophy, ethnicity

\title{
Resumo
}

Existe uma suposição naturalizada de que a sedentarização é umprocesso evolutivo natural. Nesta narrativa, o nomadismo está espectralmente presente: o nômade é umtraço, umapalavra presente que é sugerida tão adiada quanto m̃mobilidadeò ou ñransumânciaò mas o nômade parece secreto e inominável. Caso contrário, argumentamos que a sedentarização não é apenas não natural ouinevitável, mas, nos casos, é o produto de uma relação de poder colonial, de imposição forçada e violenta.

A partir do registro etnográfico coletado entre 2004 e 2017 nas terras secas de Lavalle, província de Mendoza (Argentina), procuramos mostrar dinámica nómade em diálogo com estudos e diversas abordagens teóricas sobre o nomadismo em outras partes do mundo. Para isso, articulamos propostas da filosofía nómade com estudos antropológicos, em um esforço para abordar o nomadismo com todo seu escopo e complexidade, em termos políticos, culturais e econômicos.

Palavras-chave: nomadismo, sedentário, colonialidade, deserto, pensamento nómade. 


\section{Presentación}

Una carpa que no se mueve, es una carpa en problemas.

(Referente Rom, La Plata, 2003)

En el amplio campo de saber de los estudios sobre diversidad, construcción de diferencia, procesos identitarios, construcción de subjetividad plural, subalternidad: ¿qué lugar ha ocupado y ocupa la subjetividad nómade? Siempre se ha escrito desde los sedentarios, han advertido Gilles Deleuze y Felix Guattari (1980), nunca desde los nómades. Este silencio llama la atención, cuando la realidad muestra que en la mayoría de las sociedades las poblaciones nómades sufren un persistente aislamiento, extrañamiento, descalificación, desconfianza y violencia racista; cuando no se reconoce jurídicamente su forma de ocupación territorial, situación que los va despojando cada vez más de sus lugares de origen con la venta de tierras desde la lógica capitalista. N̂Nomadismoòes frecuentemente asociado con palabras como vagabundeo, delincuencia, errancia, criminalidad. ${ }^{2}$

En el ámbito geopolítico asiático y africano así como de la Europa central y oriental, la producción antropológica sobre nomadismo es muy voluminosa, más aún bajo el rótulo de m̃omadismo pastorilò Entre algunos de los trabajos de referencia podemos mencionar los de Fredrik Barth, ${ }^{3}$ Gudrun Dahl y Anders Hjort, ${ }^{4}$ Peter P. Schweitzer, Robert Hitchcock, Megan Biesele, ${ }^{5}$ F. de Wiejer, ${ }^{6}$ Jérémie Gilbert, ${ }^{7}$ Richard Tapper, ${ }^{8}$ Barbara

${ }^{2}$ Gilbert, Jérémie (2007), NNomadic territories: a human rights approach to nomadic peoples land rightsò Human Rights Law Review, v. 7, n. 4, Oxford University Press, UK.

${ }^{3}$ Barth, Fredrik (1961), Nomads of south Persia: the Basseri tribe of the Khamseh confederacy, Allen \&Unwin, London.

${ }^{4}$ Dahl, Gudrun, Anders Hjort (1980), r̃ Some thoughts on the anthropological study of pastoralismò Nomadic Peoples, n. 5, White Horse Press, UK, pp. 11-15.

${ }^{5}$ Schweitzer, Peter P., Robert Hitchcock, Megan Biesele (eds.) (2000), Hunters and Gatherers in the Modern World: Conflict, Resistance, and Self-Determination, Berghahn Books, New York.

${ }^{6}$ de Weijer, F. (2002), ĩPastoralist vulnerability studyò Afghanistan Food Security Unit, World Food Programme, en ftp.fao.org/country/afghanistan/kuchi.pdf.

7 Gilbert, Jérémie (2007), op. cit.; Gilbert, Jérémie (2012), గ̃and rights and nomadic peoples: using international law at the local levelò Nomadic Peoples, v. 16, n. 2, White Horse Press, UK, pp. 78-83.

8 Tapper, Richard (2008), WWho are the Kuchi? Nomad self-identities in Afghanistanò The Journal of the Royal Anthropological Institute, v. 14, n. 1, The Royal Anthropological Institute of Great Britain and Ireland, UK, pp. 97-116. 
Casciarri, ${ }^{9}$ Hillary Gilbert, ${ }^{10}$ Günter Schlee, ${ }^{11}$ y la voluminosa producción reunida en la revista Nomadic Peoples. En cambio en Argentina y Latinoamérica, salvo en las investigaciones sobre el pueblo Rom, la palabra mómadeòcarece de referencia etnográfica actual. Sólo aparece mencionada en los estudios sobre amazonia colombiana y brasileña con un enfoque predominantemente ecológico ${ }^{12} \mathrm{o}$ en investigaciones centralmente históricas ${ }^{13}$ y arqueológicas. ${ }^{14}$ También podemos mencionar los estudios y análisis contemporáneos chilenos y argentinos que se clasifican dentro de un dominio de saber que pone como eje la idea de f̂rashumanciaòy ñmovilidadò(no la de nomadismo) para caracterizar un modo de producción vinculado a la actividad pastoril en la zona cordillerana. ${ }^{15}$

${ }^{9}$ Casciarri, Barbara (2009), ṙBetween market logic and comunal practices: pastoral nomad groups and globalization in contemporary Sudan (case studies from central and western Sudan)ò Nomadic peoples, vol. 13, n. 1, White Horse Press, UK, pp. 69-91.

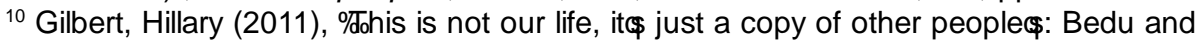
the Price of ólevelopmentôin South Sinaiò Nomadic Peoples, v. 15, n. 2, White Horse Press, UK, pp. 7-32.

11 Schlee, Günter (2013), ñTerritorializing ethnicity: the imposition of a model of statehood on pastoralists in northern Kenya and southern Ethiopiaò Ethnic and Racial Studies, v. 36, n. 5, Taylor \& Francis, UK, pp. 857-874.

${ }^{12}$ Carrera Becerra, Gabriel, E. Franky Calvo, Dany Mahecha Rubio (1999), Los n)kak: nómadas de la Amazonia colombiana, Universidad Nacional de Colombia, Colombia; Rival, Laura (2006), ñAmazonian Historical Ecologiesò The Journal of the Royal Anthropological Institute, Ethnobiology and the Science of Humankind, v. 12, The Royal Anthropological Institute of Great Britain and Ireland, UK, pp. 79-94 ; Franky Calvo, E. y Dany Mahecha Rubio (2011), Los n)kak. El último pueblo de tradición nómada contactado oficialmente en Colombia, Informe IWGIA 11, Universidad Nacional de Colombia, Colombia.

${ }^{13}$ Núñez, Andrés, Raúl Molina, Enrique Aliste, Álvaro Bello (2016), r̃Silencios geográficos en Patagonia-Aysén: territorio, nomadismo y perspectivas para re-pensar los márgenes de la nación en el siglo XIXò Magallania, vol. 44, núm. 2, Chile, pp. 107-130.

${ }^{14}$ Medina, Matías E. (2015), r̃Casas-pozo, agujeros de postes y movilidad residencial en el periodo Prehispánico tardío de las Sierras de Córdoba, Argentinaò en Salazar, J. Condiciones de posibilidad de la reproducción social en sociedades prehispánicas y coloniales tempranas en las Sierras Pampeanas (República Argentina), Centro de Estudios Históricos Prof. Carlos A. Segreti, Córdoba

${ }^{15}$ Göbel, Barbara (2002), ña arquitectura del pastoreo: uso del espacio y sistema de asentamientos en la Puna de Atacama (Susques)ò Estudios Atacameños, núm. 23, Universidad Católica del Norte, Chile, pp. 53-76; Hevilla, María Cristina y Matías Molina (2010), ñTrashumancia y nuevas movilidades en la frontera argentino-chilena de Los Andes Centralesò Revista Transporte y Territorio, núm. 3, UBA, Argentina, pp. 40-58; Tomasi, Jorge (2013), ז̃Espacialidades Pastoriles en las Tierras Altoandinas. Asentamientos y Movilidades en Susques, Puna de Atacama (Jujuy, Argentina)ò Revista de Geografía 
En buena parte del imaginario social y académico el sedentarismo es pensado como un proceso histórico m̃aturalò El nomadismo queda relegado a una etapa pasada ya superada, aquella que transitaran los cazadoresrecolectores, porque se supone que hay un proceso evolutivo por el cual las bandas de cazadores recolectores se van haciendo cada vez más r̃sedentariasòjunto con la adopción de nuevas tecnologías. ${ }^{16}$ Prevalece así la idea de que la lógica nómade pertenece a otro tiempo, siendo objeto de estudios arqueológicos, históricos y literarios.

El silencio sobre el nomadismo es doble: teórico/etnográfico y jurídico. El nómade adolece de lugar de enunciación reconocido. Es esta ausencia la que nos ha empujado a revisar los criterios que sustentan la construcción de las diferencias así como las normas sociales y/o patrones culturales socialmente hegemónicos a los cuales deben ajustarse. Nuestra perspectiva, inspirada en la nomadología de Deleuze y Guattari y Rosi Braidotti se funda en una conversación antropológica/filosófica, en el sentido de relevar prácticas y positividades nómades a la vez que de remover las condiciones y formas en que se piensa el sedentarismo y el nomadismo en busca de abrir nuevos caminos a ese pensamiento. ${ }^{17}$

Norte Grande, vol. 55, Chile, pp. 67-87; Molina Otarola, Rafael (2014), r̃Cordillera de Atacama. Movilidad, frontera y articulaciones collas-atacameñasòen Núñez, Andrés, Rafael Sánchez, Federico Arenas (eds.), Fronteras en movimiento e imaginarios geográficos. La cordillera de los andes como espacialidad sociocultural, Pontificia Universidad Católica de Chile, Chile, pp. 189-220; Maino, Valeria (2015), Trashumancia en el valle del Choapa, Los Pelambres, Origo ediciones, Chile; Gasco, Valeria Alejandra, Víctor Durán, Laura Piazze, Miguel Giardina, Guillermo Campos (2015), ñeranadas sin frontera. Etnografía de pastores en el Centro-Oeste argentinoò Revista del Museo de Antropología, vol. 8, núm. 2, IDACOR-CONICET / Facultad de Filosofía y Humanidades, Universidad Nacional de Córdoba, Argentina, pp. 133-146; Otaola, Clara, Miguel Ángel Giardina, Matew Fry, Gustavo Neme, Steven Wolverton (2016), ñooarqueología y tafonomía en pastores actuales del sur de Mendozaò Intersecciones en Antropología, núm. 17, Universidad del Centro, Argentina, pp.120-121.

16 Dentro del universo de las investigaciones arqueológicas, esta premisa teórica ha sido cuestionada por Medina (2015). El autor cuestiona el r̃síndrome agrícolaò desde el cual se entiende a la caza-recolección como una actividad marginal a la vez que se insiste en la estrategia agrícola sedentaria, posición que entiende obstaculiza comprender con rigurosidad la flexibilidad y movilidad residencial con que las sociedades tardías definían sus patrones de vida.

17 Katzer, Leticia (2015), rMárgenes de la etnicidad. De fantasmas, espectros y nomadológica indígenaò Tabula Rasa, núm. 22, Bogotá, Colombia, pp. 31-51. 
En el siguiente artículo presentamos resultados de nuestra investigación etnográfica en el secano de Lavalle, provincia de Mendoza (Argentina) (2004-2017) cuyos datos revelan nuevas dimensiones analíticas de la relación entre etnicidad y lógica nómade así como nuevas complejidades empíricas dentro del espacio etnográfico de estudio. En esta línea enmarcamos nuestro análisis dentro de enfoques epistemológicos poco convencionales como son la deconstrucción y el pensamiento nómade en conversación con reflexiones provenientes de las perspectivas poscoloniales y decoloniales y la crítica biopolítica que tensionan el paradigma de la modernidad colocando como centro de atención un sujeto y contexto social relegado, estigmatizado, exotizado, atemporalizado: el nómade y el desierto, respectivamente. A través de ello exponemos reflexiones de orden teórico/metodológico respecto de enfoques sobre el nomadismo, buscando dinamizar esta palabra diferenciándola de ñmovilidadòy r̃trashumanciaò

\section{Saberes y positividades nómades: genealogía etnográfica de un campo de exploración subalternizado}

Hay múltiples huellas en los temas de investigación que seleccionamos. Los primeros contactos con la temática que focaliza este trabajo tuvieron lugar en dos experiencias distintas, una personal y otra etnográfica. Mi interés por el nomadismo nace de una experiencia etnográfica en el contexto del conurbano platense, hace más de quince años atrás. Por el año 2003, siendo estudiante avanzada de la carrera antropología comencé el trabajo de campo en el barrio Qom de La Plata, en cuyo recorrido pasaba siempre por un conglomerado de carpas de familias rom (para el común de la gente, los gitanos). Durante meses observé el lugar desde la distancia, desde la vereda de enfrente, un poco por temor y otro poco porque no quería distraerme del tema que me convocaba y que tenía que ver específicamente con la etnicidad indígena Qom. En esas pasadas, a veces observaba más de cinco carpas, otras veces una y en algún momento ninguna, cuestión que me llamaba la atención. Una tarde me decidí a acercarme a saludarlos y a manifestarles mi inquietud. Fue así 
que me invitaron a pasar al r̂hallòde la carpa, convidándome unos mates alrededor del fuego (recuerdo que hacía mucho frío, era invierno). En ese momento todo mi esfuerzo se centraba en derribar el miedo y el prejuicio que se anteponía a la situación: me preguntaba a mí misma por qué ese miedo a que algo malo me ocurriera, miedo a que me hicieran algo dañino cuando en realidad recibía toda su calidez. La respuesta es sencilla: respecto de los gitanos siempre nos han transmitido todos los atributos negativos: sucios, tramposos, ladrones. Allí vivencié todo lo contrario: una carpa ordenada y limpia y una cálida hospitalidad. A partir de allí establecí una incipiente amistad con una jovencita. Con las mujeres adultas no tuve contacto allí (salvo con una Gadyé ï criolla para nosotrosï , casada con un joven rom allí residente) puesto que en las tardes que yo estaba en la carpa, ellas se encontraban en el centro llevando adelante su actividad de radivinar la suerteòy de venta ambulante. Al respecto la jovencita rome señaló que ese último tiempo habían tenido muchos problemas económicos que las obligaban a reforzar la actividad ambulante callejera. También que esas dificultades eran el indicio de que permanecieran allí, sin moverse, aseverando que ñuna carpa que no se mueve, es una carpa que está en problemasò El contacto con las mujeres rom adultas fue dado en otro contexto, un contexto personal. En ese entonces, a la vez que cursaba el último año de la carrera universitaria, preparaba y vendía viandas en los edificios de administración pública ubicados al frente de la plaza Moreno, de la misma ciudad. Todos los días, al finalizar la jornada laboral cruzaba dicha plaza para encontrar a las mujeres rom que adivinaban la suerte allí. Desde ese momento nos empezamos a saludar intercalando alguna conversación, siempre en tono amistoso y empático, casi de mutua identificación: todas nos encontrábamos y esperábamos como vendedoras ambulantes.

Esta descripción de tono anecdótico fue la base sobre la cual la relación entre etnicidad y nomadismo se convirtió por aquellos años en mi incipiente tema teórico de investigación. A partir de aquí, y en conexión de estos primeros registros etnográficos me puse en contacto con la asociación civil rom ñdentidad cultural romaniò con sede en capital federal, cuyos miembros eran ï y siguen siendo-militantes activos en defensa de los derechos del pueblo Rom. Con ellos compartí actividades diversas, incluido la visita a su programa radial. También me acerqué a otras fracciones 
étnicas nucleadas en otra zonas de La Plata, ${ }^{18}$ en oportunidad de lo cual una mujer rom de la tercera edad, de porte grande y voz muy gruesa con mucho enojo se limitó a decirme ñustedes los blancos nos hacen mucho dañoò a lo cual respondí que la entendía y que por eso me retiraba.

De esta incipiente etnografía se ponía al descubierto una hipótesis de trabajo: ligando la actividad económica a la tradición nomádica, los rom ordenaban su rutina sobre la movilidad. La r̂baxtò(la suerte, el destino, el azar), la venta ambulante callejera, la venta comercial de autos, la movilidad residencial, todo en conjunto aparecía ligado al movimiento y al flujo. Esta primera delimitación de un espacio de trabajo etnográfico se alimentaba de las reflexiones filosóficas sobre nomadismo y des-apropiación identitaria de Jacques Derrida, autor con el que estaba en pleno compromiso de lectura. Tenía ante mí un marco etnográfico y un problema filosófico.

Ya recibida, me veía motivada por retornar a mi provincia de origen, Mendoza, donde el tema étnico local (huarpe) se convertía en asunto público. Fue así que desvié el campo etnográfico, proyectando mi tarea de campo en esa zona.

Ahora la inquietud por la investigación se veía atravesada por una doble cuestión de tipo institucional: el tema de investigación de doctorado y la selección de un r̃ojeto de estudioà ¿era una tesis filosófica o una tesis antropológica? ¿Se trataría de un doctorado en filosofía o un doctorado en antropología?, ¿huarpes o rom? Esta inquietud fue resuelta con el asesoramiento por parte de académicos prestigiosos que frustraron mi motivación: la posibilidad de una tesis de filosofía con base antropológica, es decir, la carencia de pureza disciplinaria ${ }^{19}$ y la ausencia de enclave e interés del tema r̃gitanosòdentro del closet académico se mostraban como

${ }^{18}$ El pueblo rom no es un pueblo homogéneo. Ese es otro de los estereotipos. Por lo contrario este pueblo está constituido por múltiples etnicidades, algunas de las cuales están en guerra entre sí. Se encuentran los xoraxané, los boyash, los kalderash, los purumi, los kalé, y muchos más cada uno proveniente de diversas regiones del mundo గ̃Katzer, Leticia (2005), r̃Comunidad e identidad desde la espectrología. Un saludo al naufragio gitanoò Ponencia presentada en el I Congreso Latinoamericano de Antropología. Realizado desde el 11 al 15 de julio de 2005 en la Facultad de Humanidades y Artes de la Universidad Nacional de Rosario, Asociación Latinoamericana de Antropologíaò

19 rNo le dé dolores de cabeza a su directora, déjelos a los darwinianos con la antropología, no se meta en la filosofíaòfue la sugerencia de un filósofo foucaultiano. 
los dos aspectos que anulaban la iniciativa de un proyecto filosófico y un proyecto etnográfico con los rom.

Esta descripción, que vuelve a sonar anecdótica constituye en realidad la base de una mirada epistemológica, aquella que entiende que los temas de investigación se fundan en la experiencia, y que la relación entre nomadismo y etnicidad, atravesada por la experiencia colonial, constituye un campo de exploración subalternizado dentro de los cánones académicos y jurídico-políticos. La propia colonialidad del saber, en el sentido de Lander (2000) vuelve inexpresables o escasamente expresables en el universo académico y jurídico, formas de vida nómades, entendiendo por éstas tanto la práctica cultural nómade así como al nomadismo disciplinario.

En un esfuerzo por trascender esas barreras y encuadramientos disciplinarios purificados que impone la r̃̃onstitución moderna ${ }^{20}$ como garantía de totalidad estable, con una reverente irrespetuosidad ${ }^{21}$ para seguir la pista deconstructiva, los apartados que siguen recorren diferentes itinerarios analíticos en el marco de una conversación filosófica/ antropológica situada en un campo etnográfico concreto: el r̃desiertoòdel noreste de la provincia de Mendoza, República Argentina.

\section{Articulaciones del nomadismo en el noreste de Mendoza. Antecedentes y registros actuales}

En nuestro contexto de estudio la configuración cultural del hábitat desde una matriz móvil, en nuestra lectura, m̃ómadeờ ${ }^{2}$ ha sido en buena medida

20 Noción desarrollada por Bruno Latour (1991).

${ }^{21}$ Como señaló Roudinesco a Derrida en una carta, interrogar las obras r̃de una manera diferente a la imitación, la repetición, la adoración o el simple rechazoò (Carta de Élisabeth Roudinesco a Derrida, 6 de junio de 1985, citado en Peeters, Benoit (2013 [2010]), Derrida, FCE, Buenos Aires, p. 441).

22 Nuestra investigación etnográfica se inicia en el año 2004, delimitando como área central de estudio el NE de la provincia de Mendoza, lo que se conoce como r̃secanoòo r̃zona no irrigadaò Buena parte de esta población se adscribe étnicamente como Huarpe. Este grupo étnico, declarado extinto por décadas a partir de los 60ô continuó siendo objeto de investigaciones desde un enfoque territorial (Abraham y Prieto, 1981; Doro, 1985) y comenzó su visibilización y corporalización pública hacia fines de los 90ô proceso registrado por los académicos locales desde diferentes ángulos disciplinares: socioambiental (Prieto, 1999); arqueológico (Cahiza, 2000; Chiavazza, 2001, García, 2004) y 
desdeñado por las políticas públicas y la propia academia. Más aún, en ciertos casos se me ha cuestionado el uso mismo del término m̃ómadeò sobrevalorando al mismo tiempo la noción de ñrashumanciaòcomo noción universal autorizada para dar cuenta de dinámicas de movilidad. Situación que me ha obligado a explicitar a evaluadores ñmolestosòe ñncómodosò hasta podríamos decir r̃enojadosòcon el uso del término m̃ómadeò los numerosos argumentos teóricos antropológicos y filosóficos desarrollados durante más de media centuria de congresos y publicaciones. ¿Por qué ese enojo, esa incomodidad, esa resistencia a la instalación y visibilización del ñomadismoòcomo lugar de enunciación? A la par de estos cuestionamientos, durante un encuentro en ocasión del acto por el día de los pueblos originarios en el año 2017, referentes de organizaciones indígenas del sur mendocino explicitaron el aporte que significaba para ellos contar con el acompañamiento de afirmaciones teóricas que no limitaran su cultura a una mera actividad económica ganadera bajo el rótulo de f̂rashumanciaò

Las investigaciones etnográficas sobre m̃omadismoòse hallan ausentes en el noreste mendocino, ${ }^{23}$ limitándose en Argentina a la frontera centrooeste (San Juan hacia el norte), noroeste y centro-sur (sur de provincia de Mendoza hacia el sur) y bajo el título de ñrashumanciaòy m̃movilidadò con un enfoque centralmente económico, ecológico y arqueológico. ${ }^{24}$ Es decir que el nomadismo o es remontado a un pasado mayor a los 100 años atrás o es sesgado a la variable ecológica en cuanto actividad pastoril estacional, entendido como trashumancia. En otra dirección, además de darle presencia y actualidad etnográfica a la cuestión de la m̃movilidadò nuestra investigación ha dado cuenta de que la matriz móvil de organización social local se expresa en múltiples dimensiones más allá de lo económico

antropológico (Escolar, 2007). Este grupo étnico se ha organizado allí en once comunidades, que se nuclean alrededor de los once parajes que tiene la zona. Estos parajes cuentan cada uno con una capilla religiosa (en casos, centenarias), escuela y centro de salud. Más allá de estos parajes, las familias se disponen de manera dispersa en el extenso territorio, campo abierto, acorde a la actividad pastoril (fundamentalmente caprina, y en menor medida vacuna).

${ }^{23}$ El nomadismo en esta región sólo se ha encontrado referenciado en las investigaciones arqueológicas de Horacio Chiavazza.

${ }^{24}$ Medina, Matías E. (2015), op. cit.; Gasco, Valeria Alejandra et al. (2015), op. cit.; Otaola, Clara et al. (2016), op. cit. 
y lo ecológico/estacional. ${ }^{25}$ Así hemos dado cuenta de que prevalece y se reactualiza una lógica móvil de producción territorial en un sentido ecológico, cultural y político. ${ }^{26}$

Particularmente respecto de la región noreste de Mendoza y la población nativa allí residente, los abordajes han sido numerosos y muy variados en relación a la perspectiva teórico-metodológica. Los primeros análisis etnográficos corresponden a la primera mitad del siglo $x x,{ }^{27}$ con un renovado impulso en las décadas de los setenta y ochenta ${ }^{28}$ y complementados desde la última parte del siglo pasado por una creciente complejidad en cuanto a las variables consideradas e interpretaciones, arqueológicas, etnohistóricas, políticas, culturales y socio-ambientales. ${ }^{29}$ Así, nos

${ }^{25}$ Katzer, Leticia et al. (2017), íBio-historia del nomadismo y de la producción territorial del NE de Mendoza. Lectura interdisciplinaria desde la ecología, la arqueología y la etnografíaò Relaciones de la Sociedad Argentina de Antropología, tomo 42, núm. 2, Universidad Nacional de La Plata, pp. 345-367; Katzer, Leticia (2018a), rEspectrografías nómades del ólesiertoôdel NE de Mendoza, Rca Argentinaò Plural, núm. 2, Asociación Latinoamericana de Antropología, Argentina, pp. 55-90.

${ }^{26}$ Katzer, Leticia et al. (2017), op. cit.

${ }^{27}$ Metreaux, Alfred (1937[1929]), r̃Contribución a la etnografía y arqueología de la provincia de Mendozaò Revista de la Junta de Estudios Históricos de Mendoza, Tomo VI, núm. 15, Argentina, pp. 1-66; Canals Frau, Salvador (1946), F́Etnología de los Huarpes. Una síntesisò Anales del Instituto de Etnografía Americana, vol. 3, núm. 9, pp. 9-148.

${ }^{28}$ Pannunzio de Mulle, María (1976), r̃agunas del Rosario. Estudio Preliminar de una población de zona áridaò Anales de Arqueología y Etnología, Argentina, núm. 29, pp. 207235; Triviño, Luis (1977), Antropología del Desierto, Fundación para la Educación, la Ciencia y la Cultura, Buenos Aires; Abraham de Vázquez, Elena María y María del Rosario Prieto (1981), r̃Enfoque Diacrónico de los Cambios Ecológicos y de las Adaptaciones Humanas en el NE Árido Mendocinoò Cuadernos del CEIFAR, núm. 8, Mendoza, Argentina, pp.109-139; Bustos, R. M. (1983), íFactores potenciales de desarrollo o estancamiento en una zona árida, Departamento de Lavalle, Mendozaò Deserta, núm. 7, Mendoza, Argentina, pp. 290-315; Micheli, Catalina (1983), Los Huarpes protohistóricos, Universidad Nacional de San Juan, San Juan.

${ }^{29}$ Parisii, M. (1994), ñalgunos datos de las poblaciones prehispánicas del Norte y Centro Oeste de Mendoza y su relación con la dominación inca del áreaò Xama, núm. 45, Argentina, pp. 51-69; Lacoste, Pablo (1998), Lavalle, La Paz y Santa Rosa. Historia y Perspectivas, Diario Uno, Mendoza; Prieto, M. (1999), ñAntecedentes huarpes de los pobladores del Noreste de la Provincia de Mendozaò Informe del Instituto de Ciencias Humanas, Sociales y Ambientales, Mendoza; Chiavazza, Horacio (2001), Las Antiguas poblaciones de las arenas. Arqueología en las tierras áridas del noreste mendocino, Ediciones Culturales de Mendoza-Serie Bienes Patrimoniales Mendoza, Mendoza; Montaña, Elma et al. (2005), గ̃os Espacios Invisibles. Subordinación, Marginalidad y Exclusión de los Territorios no irrigados en las Tierras Secas de Mendoza, Argentinaò 
encontramos con una extensa y voluminosa producción científica sobre la región noreste, en la cual, sin embargo, el m̃omadismoòno se ha mostrado como un tema central de análisis.

A pesar del silencio académico y jurídico, el registro de la lógica móvil de vida social en el noreste de Mendoza es de larga data y señalado de manera frecuente por los cronistas primero y luego en las etnografías e historiografías locales de primera mitad de siglo xx. Ovalle (1646) describía a la población nativa como ñuenos rastreadoresò carentes de ñugar señaladoòy a sus viviendas como ñportátiles de pellejosò De igual forma, Zamorano ${ }^{30}$ hablaba de ñiviendas temporariasòcomo ñefugio transitorio creación efímera, que no ha de sostenerse mayormente en el tiempoò Además de estas variables, los registros arqueológicos, historiográficos y etnográficos dan cuenta de una lógica móvil de producción territorial en un sentido cultural y político. ${ }^{31}$ Investigaciones arqueológicas en el lugar ${ }^{32}$ han dado cuenta de la presencia de caseríos con habitaciones correspondientes a unidades domésticas semisubterráneas (pozos semicirculares recubiertos con ramas de jarilla y sostenidos con palos de algarrobo) con una datación de 2000 años de antigüedad) muy similares a los r̃socavones

Región y Sociedad, vol. 17, núm. 32, Hermosillo, México, pp. 3-32; Manzur, Gregorio (2007), Guanacache, las tierras de la sed, Fundación Marañón, Mendoza; Pastor, Gabriela y Laura Torres (2010), ñTurismo en territorios periféricos? Algunas reflexiones a propósito de un estudio de caso en el Đesierto de Lavalleô Argentinaò Estudios y perspectivas en turismo, vol. 19, núm. 2, Argentina, pp. 163- 181; Saldi, Leticia (2016), îEl Estado-sistema frente a la cuestión indígena. Análisis de los modos de reconocimiento de derechos a la identidad Huarpes, al agua y a tierras comunales en Mendoza (Argentina)ò Universitas Humanisticas, núm. 82, Colombia, en http://www.revistas.javeriana.edu.co/ index.php/ univhumanistica/article

30 Zamorano, M. (1950), ñAcerca de la vivienda natural en la república Argentina y especialmente en Mendozaò Anales de Arqueología y Etnología, Tomo XI, Mendoza, p. 93.

${ }^{31}$ Katzer, Leticia et al. (2017), op. cit.

${ }^{32}$ Chiavazza, Horacio (2009), ñGarganta seca y arena en las botas: prospectando antecedentes arqueológicos de las tierras áridas del noreste mendocino (Centro Oeste Argentino)à Arqueología Iberoamericana, núm. 1, pp. 41-77; Chiavazza, Horacio (2010), ñocupaciones en antiguos ambientes de humedal de las tierras bajas del norte de Mendoza: sitio Tulumaya (PA70)ò Intersecciones en Antropología, núm. 11, Argentina, pp. 41-57; Chiavazza, Horacio (2013), r̃̃̂No tan simplesô pesca y horticultura entre grupos originarios del norte de Mendozaò Comechingonia virtual, Revista Electrónica de Arqueología, núm. 1, Argentina, pp. 27-45; Chiavazza, Horacio (2015), ĩPescadores y horticultores ceramistas del valle de Mendozaò Xama. Serie Monografías, núm. 5, Argentina, pp. 45-62. 
en la arenaòmencionados en documentos referenciados en las etnografías de mediados del siglo xx, como las de Canals Frau (1942) y Vignati (1953) correspondientes a los siglos $\mathrm{xV}$ al $\mathrm{XVIII.}{ }^{33} \mathrm{En}$ los registros etnohistóricos e historiográficos hay una asociación explicita entre ñmovilidadòy ñviviendaò (ñviviendas temporariasò) lo que a su vez es señalado como signo de inferioridad y carencia de progreso así como destinado a la r̃desapariciónò ${ }^{34}$ Nuestros registros etnográficos actuales también revelan dicha asociación. La movilidad se expresa en forma de edificación local, la r̃quinchaò una técnica nativa que se adapta de manera muy eficiente a las características ambientales, optimiza el uso de los recursos naturales locales (arcilla, arena, palo de algarrobo, jarilla, caña, entre otros) y se acomoda a las condiciones de movilidad de los nativos (en la medida en que se trata de una técnica de construcción flexible, permite su traslado, armado y desarmado de manera rápida).

Los registros historiográficos, arqueológicos y los que reunimos en nuestro trabajo de campo nos dan indicios de una continua conexión entre el nomadismo y ciertas formas de configuración del hábitat, en términos simbólicos y en términos de mecanismos de utilización de los recursos naturales locales. En este sentido sumamos a la perspectiva de análisis los aportes de las investigaciones sobre ñerritorio étnicoòde Alicia Barabas ${ }^{35}$ entendido como el territorio donde se inscriben las prácticas y símbolos culturales a través del tiempo. En esto, como señalamos, las formas de edificación de viviendas y emplazamientos comunitarios toman particular relevancia.

Respecto a los estudios sobre la arquitectura nativa, un antecedente lo constituye los trabajos de Gabriela Pastor, siendo también abordado como una de las variables dentro de las dinámicas ecológicas del uso de la madera muerta. ${ }^{36}$ Las edificaciones vernáculas, construidas con medios y técnicas tradicionales, han sido consideradas como constitutivas de la cultura y como

${ }^{33}$ Chiavazza, Horacio (2015), op. cit.

${ }^{34}$ Katzer, Leticia (2018a), op. cit.

${ }^{35}$ Barabas, Alicia (coord.) (2003), Diálogos con el territorio. Colección Etnografía de los pueblos indígenas de México, Tomos I a IV, INAH, México.

${ }^{36}$ Velez, Silvina, Natacha P.Chacoff, Claudia M. Camposa (2016), r̂́Seed predation and removal from feces in a dry ecosystemò Basic and Applied Ecology, n. 17, Journal of the Ecological Society of Germany, Austria and Switzerland, pp. 145-154. 
parte del patrimonio material e inmaterial. ${ }^{37}$ A estas investigaciones nosotros le anexamos la variable de la m̃movilidadò apuntando a los registros etnográficos de la variabilidad de estructuras edilicias -respecto a lugar de emplazamiento y técnica de construcción- acordes a los requerimientos diferenciados de la vida social, política, económica y religiosa local.

A partir de un extenso relevamiento etnográfico basado en trabajo de campo con observación participante, relevamiento de historias de vida, entrevistas semiestructuradas y conversaciones abiertas durante 14 años (lo cual a su vez ha implicado la identificación y acompañamiento en momentos significativos en la producción y organización de la vida nativa tales como salidas de recolección de frutos, madera y leña, salidas de caza y campeo de animales, participación en actividades de cosecha, participación en eventos religiosos) observamos así diversas formas de organización territorial estructuradas sobre la ñmovilidadòen dimensiones centrales como el trabajo (pastoreo, cosecha, caza y recolección), la residencia (formas de viviendas ï puestosï , ${ }^{38}$ ramadas, riales, reparos) y el manejo de recursos naturales locales (bosques de algarrobo y chañar ï fruto, madera y leñaï ). Así hemos establecido un mapa con los m̃odos de movilidadòen el cual identificamos zona de pastoreo y caza, rial de recolección, puesto, ramadas con fines religiosos, rial/ramada residencial temporaria para eventos religiosos. Estos mapas se nutren del material aportado por datos arqueológicos e históricos sobre movilidad, uso de recursos naturales estratégicos y tipos de viviendas en la zona, incluyendo la determinación del rol de los recursos naturales estratégicos así como su instrumentalización jurídico-política de acuerdo a procesos históricos, económicos y cambios legales en cuanto a reglamentación territorial y derechos de los pueblos nativos, los cuales he publicado en otros trabajos. ${ }^{39}$

37 Pastor, Gabriela C. (2005), TPatrimonio, vivienda y agua en el Paisaje del Noreste Mendocino. El agua en Iberoamérica. Uso y gestión del agua en tierras secasò El agua en Iberoamérica, vol. XI, Mendoza, pp. 79-92;

${ }^{38}$ El ñpuestoòes una unidad residencial y productiva que incluye la vivienda o habitación y el corral de animales.

${ }^{39}$ Tal como lo he desarrollado en otros trabajos, la población adscripta como Huarpe ha protagonizado tres grandes procesos de territorialización, entendidos como procesos de colonización y gubernamentalizaciónde acuerdo a modelos sedentarios (Katzer, 2018): el inicio del proceso de gubernamentalización en contexto colonial, la gubernamentalización republicana y la etnogubernamentalización neoliberal. Antes del arribo español en el siglo XVI (1551-1561) y de acuerdo al registro arqueológico y 
Para dar cuenta del circuito de movilidad hemos tomado como área de referencia central de estudio, el área correspondiente a la Reserva Bosques Telteca, zona que nuestro registro etnográfico revela como lugar de condensación simbólica, política, social y económica de la lógica nativa móvil. En la Reserva residen miembros de tres comunidades Huarpes diferentes, a saber: Comunidad Juan Bautista Villegas (El Cavadito), Comunidad Secundino Taltenca (El Retiro) y comunidad Lagunas del Rosario (Lagunas del Rosario). En este marco relevamos y analizamos las formas de organización socio-económicas de las rutinas de vida de las familias que allí residen mediante el registro etnográfico de sus rutinas.

\section{Circuito de movilidad. Nodos}

La identificación de los nativos con la referencia nómade se expresa en la palabra r̃camperoò La figura de nómade coincide con la de r̃camperoò el

etnohistórico, los Huarpes se asentaban en y entre espacios en torno al agua en sus diferentes manifestaciones (cauces, charcas, lagunas, pantanos, vegas) puesto que se trata de un territorio extremadamente árido (Chiavazza, 2015). Es decir que el nomadismo estaba marcado fundamentalmente por el acceso a los recursos naturales (fundamentalmente el agua) y a los circuitos de caza y recolección y su modo de residencia se instrumentalizaba por medio de la construcción de viviendas-pozo o socavones que se practicaban en laderas de los médanos construidos con los recursos naturales nativos (jarilla y barro) conformes al patrón constructivo expeditivo (Katzer et al., 2017, Katzer, 2018). Este modelo se vio violentado con la llegada de los españoles, quienes buscaron asentarlos en un modelo de residencia concentrado en pueblos. Es este el momento en que comienza a institucionalizarse el ñpuestoò como unidad residencial y productiva de ganadería. Si bien con distintos recursos simbólicos y dispositivos de poder, los tres procesos colonialistas fueron instituyendo dinámicas de sedentarización. En el primero, mediante la creación de r̃educcionesò o ñpueblos de indiosò fomento de unidades productivas ganaderas y procesos de evangelización. En el segundo (r̃modelo republicanoò de territorialización) mediante la demarcación jurisdiccional de departamentos con respectivas villas, la Ley de Venta de Tierras Públicas, el otorgamiento de tierras para que se asienten y las produzcan y la fijación del dispositivo de ñpapeleta de conchavoò para controlar la circulación de las personas ï Katzer, 2009ï ). Se configura y reconfigura así toda una reglamentación sobre los mecanismos de ocupación, enajenación, venta, parcelamiento y explotación del recurso tierra (Ley de 1862, 1866, 1870, 1876, 1877) (Katzer, 2018). El tercer proceso/modelo (etnogubernamental, modelo del pluralismo cultural) está marcado por la creación de r̃comunidades indígenasò en tanto ñpersonas jurídicasò (año1999) bajo la lógica de la asociación una comunidad/un territorio disponiendo por reglamentación que ños miembros de las comunidades deben radicarse en las tierras que ocupanò (ldem). 
que campea, el que sale a campear, el que sale a cortar el rastro. Las campeadas constituyen desplazamientos esporádicos por parte de la población adulta nativa asociada a su vez a los requerimientos de la actividad del campo, el cuidado de los animales, la caza y la recolección. Puede ser individual o colectiva. En estas campeadas suele usarse el humo como forma de comunicación de los diferentes r̃astrosò

ñSalir a campearòtiene expresiones múltiples. Tiene que ver con la actividad ganadera, por cuanto se trata del arreo y búsqueda de animales (fundamentalmente cabras, y en menor medida vacas). Salir a campear es salir de caza, salir a cortar el rastro de animales, ra ver si se pilla algoò y también poner a prueba, y luego exponer, la potencialidad de los hombres como ñastreadoresòy r̃cazadoresòdurante el nomadismo; se muestra qué y cuánto se ha ñilladoòy cuántos animales son encontrados. Así, en la estética de los puestos se destacan elementos vinculados a la destreza de caballos y de caza: emblemas de destrezas como cazadores, rastreadores y r̃campeada en generalò hay boleadoras, alforjas, monturas, rebenques, caparazones de quirquincho, cueros de pumas cazados, patas y colas de león (puma concolor); todos esos elementos son las m̃arcasò de la potencialidad de los hombres en sus vivencias de r̃astreadoresòy r̃cazadoresòdurante el nomadismo. Durante la campeada los individuos conforman r̃uevas/reparosòen las laderas de los médanos de arena como modo de residencia; los mismos socavones conformes al patrón constructivo expeditivo que se han sido registrados arqueológica y etnohistóricamente

La ñunta de animalesòo ñpialadaòse realiza en el mes de abril. Es una actividad colectiva y masculina, a través de la cual se junta el ganado para su marcación y señado, y para efectuar la vacunación. La ñpialadaòconsiste en enlazar las dos patas traseras o delanteras para marcar al animal. Enlazan así al animal mientras están corriendo para detenerlo y tirarlo al piso. Cuando se determina la fecha para hacer la recogida de animales, la juntada se hace entre todos. Pueden durar de dos hasta tres semanas, periodo de tiempo en el que los hombres se ausentan de los hogares.

r̃Campearòtambién incluye a las rutinas de recolección de algarroba y chañar. La recolección del chañar se realiza en los meses de enero y febrero. La recolección de la algarroba verde (algarroba fresca) se realiza en febrero-marzo; la recolección de algarroba seca con la que se hace el 
patay se realiza en marzo-abril. Hasta no hace muchos años atrás se conformaban lo que los nativos denominan ñialesò que constituyen una forma de choza/reparo sobre los algarrobos hechas con palos y ramas de jarilla. Este rial funciona como vivienda temporaria durante la estadía de recolección.

La rutina ritual-religiosa anual también implica desplazamiento residencial temporario, puesto que las familias se trasladan a la vivienda temporaria (la ñamadaò durante el tiempo que transcurre el ritual (tres días). Las ramadas constituyen la reconfiguración actualizada de las tolderías, siendo constituidas por cuatro troncos de algarrobo con un techo elaborado con cañas y ramas de jarilla. Cada familia arma su ramada en cada uno de los lugares donde se realizan las fiestas religiosas. Lejos de reducirse a una práctica religiosa, se vincula mucho más a un recurso social local para reproducir la práctica de la itinerancia nómade.

El r̂̉aile de San Vicenteò que es un ritual de agradecimiento de la lluvia, es otra fiesta popular que activa la movilidad, puesto que todos se trasladan durante dos o tres días. Hay en el campo varias ramadas de San Vicente esparcidas. La distribución de lugares tiene una estructura circular: cocina (fuego), ramada donde se acuestan los niños, fuego (entre la cocina y la ramada de niños) y la ramada general con los asientos, con disposición circular.

Campear también es una forma de conocer el mundo, una forma de activar la memoria y una forma de poner en circulación esos saberes como las vivencias y experiencias de los antepasados. El ñastroòconstituye la marca desde la cual el que campea toma conocimiento de lo que le rodea.

Salir a campear es salir a encontrarse con la imprevisibilidad del universo. Es decir, es un andar que conecta con el mundo de lo Otro, y que por tanto, conecta con la religiosidad. Salir a campear es merodear y ver qué pasa, qué acontece, si pasa la luz mala, si aparece algún evento imprevisible, con la expectativa siempre de que algo suceda. No importa qué. Aquí lo relevante es la imprevisibilidad de la aparición de alguna figura de alteridad, que ponga ante los ojos la alteridad. El campear expone a la gente ante las raparicionesò $Y$ es que el nomadismo ha estado vinculado a la religiosidad desde siempre. El nomadismo tiene una estructura mesiánica; hay una mesianisidad (que no es lo mismo que mesianismo) sin mesías, sino como aquello que lo liga a lo mesiánico, a lo que viene adviene, lo por venir 
imprevisible e inesperado, la espera del advenimiento del otro, de aquello que circula. Hasta los santos y vírgenes se mudan, las capillitas son abandonadas y vueltas a hacer en otro sitio.

Por último se registra el desplazamiento familiar entre la vivienda ubicada en el paraje y el puesto así como desde éstos a la vivienda que se arrienda a la zona irrigada durante la época de la cosecha de uva entre febrero y abril (familias enteras con niños, mujeres y varones solos).

\section{Tipos de emplazamientos/nodos de movilidad}

Podemos identificar tres grandes áreas donde los nativos llevan adelante sus rutinas, de acuerdo a un circuito de movilidad, a saber: los parajes, la zona de pastoreo, caza y recolección y la zona de cosecha. Los parajes funcionan como centros cívico-ceremoniales, puesto que presentan toda la infraestructura educativa, religiosa y sanitaria (escuela, centro de salud y capilla). Allí mismo se disponen ramadas o ñialcitosò como la gente nativa le llama. Luego nos encontramos con la zona de pastoreo, caza y recolección (campo abierto) y finalmente la zona de trabajo de cosecha (fincas aledañas, pertenecientes a lo que se conoce como r̃zona irrigadaò). Así el circuito de movilidad articula diferentes nodos, los cuales condensan actividad económica, social y religiosa a la vez. Estos nodos son los siguientes:

ï Reparo cueva en médano (durante estadía de campeada (caza/campeo de animales)

ï Puesto (unidad residencial y productiva con corral y pozo balde).

ï Rial de recolección (choza de forma triangular construida con palos de algarrobo y techada con jarilla). Utilizada durante la estadía de recolección de chañar y algarroba (enero-marzo).

ï Ramada/rial de San Vicente (estructura hecha con horcones de algarrobo techada con jarilla). Usada en ocasión del ritual de San Vicente, ritual rogativo y de agradecimiento de la lluvia) (enero-febrero).

ï Vivienda paraje (unidad residencial localizada en el centro cívico; en algunos casos cuentan con corral).

ï Ramada/rial paraje (estructura hecha con horcones de algarrobo techada con jarilla usada en ocasión del ritual religioso. Las familias r̃se hacen un rialcitoò para las fiestas).

ï Vivienda en zona irrigada (alquilada anual o temporalmente durante la temporada de cosecha de uva (febrero-marzo-abril). 
El nomadismo en tanto marco cultural y modo de producción territorial se registra en las formas de trabajo y de residencia (pastoreo, recolección y caza), en los mecanismos de utilización de recursos (recolección de frutos y leña seca de los bosques, tierra, agua, pasturas), en las formas de comunicación (a través del humo y de las formas de los bordos durante las campeadas) y en las formas de la religiosidad. Podemos sostener así dos grandes afirmaciones: 1) el nomadismo no es una práctica estática sino que se transforma con el tiempo y 2) el nomadismo no se reduce a una actividad ganadera. Ser nómade en el secano hoy es salir a campear, es salir a cortar el rastro de las personas y los animales, salir a cazar, salir a recolectar los frutos del chañar y la algarroba, salir a recolectar leña, salir a merodear en las ramadas durante las rutinas religiosas, salir a encontrarse con la imprevisibilidad del universo, salir a encontrarse con los espíritus de los antiguos.

\section{Enfoques sobre el nomadismo. Discusión}

Como ya señalamos respecto al modo de abordaje, problematización y variables consideradas se observa que los estudios sobre r̃movilidad humanaòen Argentina se han llevado adelante bajo la nomenclatura de Ĩrashumanciaòy r̃movilidadò con un enfoque centralmente económico/ ecológico y arqueológico. Respecto de estas categorizaciones varios autores referentes de la línea inglesa de estudios de nomadismo han advertido que la definición del nomadismo como la movilidad de un lugar a otro en razón de la actividad pastoril debe ser criticada, puesto que m̃ómadaò como categoría analítica es irreductible a pastoreo y trashumancia. ${ }^{40}$ También cabe señalar que la distinción entre m̃omadismoòy r̃trashumanciaò ya es explicitada en la filosofía francesa posestructuralista de Deleuze y Guattari. ${ }^{41}$

Entonces nos surge la interrogante: ¿por qué este silencio teórico y jurídico respecto a la lógica nómade? Creemos encontrar algunas tentativas

40 Tapper, Richard (2008), op. cit.; Marchi, Paolo (2010), ñThe right to health of nomadic groupsò Nomadic Peoples, v. 14, n.1, pp. 31-50.

${ }^{41}$ Deleuze, Gilles, Felix Guattari (1980), Mille plateaux (capitalisme y schizophénie), Minuit, Paris. 
de respuestas a este interrogante en los aportes de las filosofías nómades así como en la crítica biopolítica, focalizada en el análisis de los parámetros de estructuración de la vida social propios de la gubernamentalidad. ${ }^{42}$ En esta lectura sostenemos que existe un campo de conflictividad entre los mecanismos biopolíticos y de gubernamentalidad (los cuales promueven la productividad, el arraigo, la radicación, el sedentarismo) y aquellos devenires que procuran realizar posibilidades de vida no reconocidas en la normatividad, como es el devenir nómade.

La lógica de la gubernamentalidad, la lógica bipolítica es sedentaria: siempre ha buscado y busca producir territorios ordenados, productivos y rentables, con la circulación estrictamente regulada y controlada. Desde este esquema el territorio nómade es clasificado como tierra improductiva, vacía, mulaò a ser colonizada. No se reconocen como jurídicamente legítimas las formas nómades de uso y regulación del territorio, cuestión

42 Nuestra perspectiva analítica coincide con aquella que articula gubernamentalidad, colonialidad y etnicidad ï Bhabha, Homi K. (1990), ñThe other question, difference, discrimination, and the discourse of colonialismò en Russell Ferguson, Martha Gever, Thinh Minhha y Comell West (eds.), Out There, Marginalization and Contemporary Cultures, Mit Press, New York; Pels, Peter (1997), ñThe Anthropology of colonialism: culture, History and the Emergence of Western Governmentality Annual Review of Anthropology, v. 26, Palo Alto, California, pp. 163-83; Amselle, Jean-Loup, Elikia Mßokolo (1999), îPrefacioò en Amselle, Jean-Loup, Elikia Mßokolo (eds.), Au coeur de l'ethnie, La Découverte, París, pp. I-IXï y se enmarca dentro de los estudios de gubernamentalidad entre cuyos referentes podemos mencionar a: Ferguson, James, Akhil Gupta (2002), ñSpatializing states: toward an ethnography of neoliberal governmentalityò American Ethnologist, v. 29., n. 4, pp. 981-1002; Restrepo, Eduardo (2004), riBiopolítica y alteridad: Dilemas de la etnización de las Colombias Negrasò en Eduardo Restrepo y Axel Rojas (eds.), Conflicto e (in)visibilidad. Retos en los estudios de la gente negra en Colombia, Popayán, Editorial Universidad del Cauca, Colombia, pp. 271-301; Castro-Gómez, Sergio (2005), La Hybris del punto cero. Ciencia, raza e ilustración en la Nueva Granada (1750-1816), Pontificia Universidad Javeriana, Bogotá; Rabinow, Paul, Nicolas Rose (2006), ṙBiopower todayò Biosocieties, n. 1, Springer USA, pp. 195-217; Boccara, Guillaume (2007), r̃Chile y đ́usô pueblos indígenas. De la invisibilización-subalternización del indígena a la nueva conquista espiritual de las fronteras del capitalismo globalizado (siglos XIX-XXI)ò en Sociedades en movimiento. Los Pueblos indígenas de América Latina en el siglo XIX, IEHS, Tandil, pp. 261-273; Cajigas-Rotundo, Juan Camilo (2007), r̃a biocolonialidad del poder. Amazonia, biodiversidad y ecocapitalismoò en Grosfoguel, Ramón y Santiago Castro-Gomez (eds.), El giro decolonial. Reflexiones para una diversidad epistémica más allá del capitalismo global, Siglo XXI, Bogotá, pp. 169-93; Werry, Margaret (2008), ñTourism, race and the state of nature. On the bio-poetics of governmentò Cultural Studies, v. 22, n. 3, Routledge, UK, pp. 391-411. 
ampliamente abordada en diferentes países por Jérémie Gilbert. ${ }^{43}$

Al igual como lo analizara Said (1978) con el ñorientalismoò el sedentarismo es una expresión cultural del imperialismo, y expresión colonial de la cultura. Y en nuestra perspectiva, la especificidad de esta expresión colonial reside en su configuración biopolítica: en tanto objetos coloniales producen los r̃ojetos étnicosòcomo r̃cuerpos sedentariosò

En la cultura de la r̃diferencia como-coloniaòtal como la hemos llamado ${ }^{44}$ en toda clausura de sujeto, se delimita una morada a ser habitada, apropiada, dominada a la que se está obligado a «pertenecer», a radicarse y permanecer. Y es una colonialidad de la cultura que se vuelve violenta, cuando se atribuye la universalidad y coloniza, dando lugar al fenómeno de la ocupación fundado en una supuesta filiación, radicación y pertenencia/ permanencia de origen. Pero t̂habitaròsignifica colonizar y tiene siguiendo a Derrida ${ }^{45}$ un ñalor descaminanteò (ñvaleur de routanteò). Habitar es radicarse, puesto que la continuidad, permanencia y regularidad la da la radicación. El habitar responde a la economía de la apropiación y del dominio de sí, a la lógica de la individualización orgánica, todo lo cual se identifica con la lógica sedentaria. ${ }^{46}$ Ésta es la lógica de la distribución en espacios cerrados, analíticamente fraccionados y cuya comunicación interna y externa, se halla por completo regulada (el espacio sedentario es el espacio estriado por muros, lindes y caminos). Una lógica ausente en los r̃desiertosò Así

é la idea de ñabitaròy de r̂hábitatòtiene que ver con la estrategia, la adaptación, la replicabilidad. Habitar/ocupar es: 1) un modo de relación colonial que implica la apropiación/cubrimiento pleno por un sujeto; 2) un modo de devenir, estar en el espacio de manera calculada, estratégica, analítica, productiva, apropiante, interesada; 3) estar activo, producir, calcular; 4) convertir el espacio

${ }^{43}$ Gilbert, Jérémie (2007), NNomadic territories: a human rights approach to nomadic peoples land rightsò Human Rights Law Review, v. 7, n. 4, Oxford University Press, UK, pp. 681 ï 716.

${ }^{44}$ Katzer, Leticia (2016), ñiferencia-como-colonia, gubernamentalidad/biopolítica y vivir bien (en común): derivaciones decoloniales del pensamiento de Derrida, Foucault y la crítica poscolonialò Tabula Rasa, núm. 25, Bogotá, Colombia, pp. 317-362

${ }^{45}$ Derrida, Jacques (1996), Le monoliguisme de lëautre, Galilée, Paris, p. 83.

${ }^{46}$ Deleuze, Gilles, Felix Guattari (1980), op. cit. 
de vida en patrimonio del sujeto que lo habita, el habitante. El espacio habitado es en esta configuración, fuerza útil desplegada en el trabajo, y es configurado, gestionado y regulado a partir de la fórmula biopolítica. ${ }^{47}$

Uno de los principios biopolíticos fundamentales es la sedentarización de la vida en común así como la objetivación y delimitación analítica del espacio. La organización analítica del asentamiento, la urbanización y la limitación de la circulación poblacional han sido caracterizadas como ejes en la consolidación de la gubernamentalidad. ${ }^{48}$ r̂Hacer viviròa la población es maximizar su productividad en función de su asentamiento, concentración poblacional y estabilidad circulatoria. ${ }^{49}$ Así, hay un nexo entre biopolítica, gubernamentalidad y sedentarismo. Se trata de la espacialización/territorialización de la vida-en-común en la forma del T̃ábitatờhabitación: La vida en común es espacializada, territorializada, estriada en la forma del ñábitatò r̂Hábitatò término que proviene de las ciencias naturales, refiere al espacio ocupado por una población que garantiza su reproducción y permanencia en el tiempo. En cambio la lógica nómade, del asedio, trata de los agenciamientos que se dispersan y que no permanecen de manera continua y contigua en el mismo lugar.

La legislación indígena vigente, prescribe el arraigo y radicación a un espacio fijo: por principio legislativo ños indígenas deben radicarse en las tierras que poseenò El artículo 12 de la ley 23.302 en Argentina, señala que los adjudicatarios de tierras están obligados a radicarse en las tierras asignadas y trabajarlas. Se deduce de ello que la r̃movilidadòes improductiva y conducente a la pobreza.

Pero tal como lo han señalado Deleuze y Guattari las sociedades nómadas no son sociedades de penuria ni de subsistencia, sino todo lo contrario, ricas, ricas en capital liso y circulante; sociedades de acción libre y de espacio liso, esto quiere decir, quiere decir abierto, circulante, móvil y desértico. A diferencia del espacio estriado del sedentario, el espacio liso es aquél que carece de división, origen, regulación, medida calculada.

${ }^{47}$ Katzer, Leticia (2009), op. cit., pp. 70-71.

${ }^{48}$ Foucault, Michel (2004[1977-1978]), Sécurité, territoire, population. Curso en el Collègue de France, Seuil/Gallimard, Paris.

${ }^{49}$ Foucault, Michel (1976), r̈Bio-histoire et bio-politiqueò Le Monde, Dits et Ecrits, tomo III, texto 179, Francia. 
El espacio liso es materia, energía fluyente. T̃Desérticoòno en el sentido geográfico sino en el sentido político. Desierto es espacio liso, en el sentido de una espacialidad inhabitable, ajena a la adscripción de f̂abitanteò ajena a la política de la apropiación, donde prevalece el fluir de fuerzas móviles y de trazos sin formas definidas, donde prima la expectativa del porvenir, del advenimiento. Es lo contrario de T̂hábitatò término que proviene de las ciencias naturales y significa espacio colonizado, apropiado desde una lógica de la fijación. La experiencia desértica es una experiencia de desapropiación. En los desiertos no hay universos, referencias, imágenes definidas. Los desiertos son pluriversos, carentes de centro y de origen. Son espacios cuyo devenir se vertebra desde las huellas, las huellas que van dejando los vivientes y sus trayectorias en el mismo andar.

Sin embargo, hay muy arraigados ciertos marcos ideológicos y culturales que obstaculizan pensar sobre las formas dinámicas con que las personas habitamos el mundo; hay una polaridad sedentarismo/nomadismo que esencializa y estabiliza cada una de ellas, cuando en realidad se mezclan y confunden. Se hace necesario dinamizar los conceptos de sedentarismo y nomadismo, que se muestran en realidad como categorías para nada rígidas. ${ }^{50}$ Los espacios lisos y estriados se encuentran en permanente combinación.

El nomadismo es un modo de vida que se actualiza y reelabora en múltiples contextos y a través de múltiples formas. El nomadismo es una categoría más global que puede incluir o no a una práctica trashumante (un caso paradigmático es el pueblo rom, que no es trashumante), que puede incluir o no a una actividad ganadera/pastora. Si bien esto está muy reconocido en ciertas filosofías, no tiene el mismo eco en la producción antropológica hegemónica americana, donde el nomadismo no pareciera ser un tema central de preocupación e interés. Pareciera instalarse un supuesto naturalizado de que la sedentarización es un proceso evolutivo natural, cuando en realidad la sedentarización no sólo no es natural ni inevitable sino que en casos es producto de una relación de poder colonial, de una imposición forzada y violenta.

Tal como encabezamos este trabajo, para los nómades circular, moverse, trasladarse constituye es signo de riqueza, bienestar, potenciación viviente,

${ }^{50}$ Katzer, Leticia (2018b), op. cit. 
alegría, todo lo contrario a como lo simboliza y experimenta el sedentario, preocupado por el orden, el cálculo del interés, la medida. El espacio nómade es un espacio político, que abre el juego a la política rizomática, ${ }^{51}$ es decir, la política que articula agenciamientos múltiples, que expone e institucionaliza los flujos múltiples y móviles de la materialidad.

\section{Consideraciones finales}

La matriz moderna y la razón técnica desde la que se estructura la manera de vivir en el espacio dan cuenta de la persistencia de la relación colonial entre el modelo sedentario y el modelo nómade. Hay un colonialismo del lenguaje jurídico, administrativo y teórico, que limita las formas en que los flujos móviles de la materialidad humana pueden expresarse y reconocerse en la esfera pública. Estos formatos generan desigualdades de legitimidad puesto que las geopolíticas del conocimiento centrifican y entronizan el sedentarismo como lugar de enunciación y subordinan/inferiorizan, subalternizan e invisibilizan las prácticas nómades y desérticas. En estas dinámicas, familias que se trasladan, que m̃merodeanòtraspasando fronteras culturales, jurídicas y estatales sufren la exclusión a la vez que eligen el aislamiento.

Se torna necesario discutir el supuesto naturalizado de que la vida humana se teje a partir de un conjunto de relaciones regulares, permanentes, estables, analíticas y productivas y en cuya administración calculada/ interesada se garantiza el éxito de la vida ciudadana. La legislación vigente, prescribe el arraigo y radicación a un espacio fijo. Insiste en la asociación unidad poblacional/unidad jurídica/unidad territorial fija. Del lado del campo de saber hay un silencio cómplice y una deslocalización y sublimación del nómade según los casos bajo las nomenclaturas de una idea generalizada de r̃movilidadòo ñrashumanciaò ponderando los factores ecológicos e invisibilizando/marginalizando el aspecto cultural y político. Por fuera de estos formatos en realidad lo que hay es una red de itinerarios que superponen territorialidades múltiples y móviles. Por ello creemos que la revisión crítica debe apuntar tanto a los marcos legislativos como al propio campo de saber académico.

51 r̃Rizomaòes un concepto filosófico propuesto y desarrollado por Deleuze y Guattari. 


\section{Bibliografía}

Abraham de Vázquez, Elena María y María del Rosario Prieto (1981), f́Enfoque Diacrónico de los Cambios Ecológicos y de las Adaptaciones Humanas en el NE Árido Mendocinoò Cuadernos del CEIFAR, núm. 8, Mendoza, Argentina.

Amselle, Jean-Loup, Elikia Mßokolo (1999), íPrefacioòen Amselle, JeanLoup, Elikia Mßokolo (eds.), Au coeur de l'ethnie, La Découverte, París, pp. I-IX.

Antón Burgos, Francisco Javier (2000), îNomadismo ganadero y trashumancia: balance de una cultura basada en su compatibilidad con el medio ambienteò Anales de Geografía de la Universidad Complutense, núm. 20, Madrid.

Barabas, Alicia (coord.) (2003), Diálogos con el territorio. Colección Etnografía de los pueblos indígenas de México, Tomos I a Iv, INAH, México. Barth, Fredrik (1961), Nomads of south Persia: the Basseri tribe of the Khamseh confederacy, Allen \&Unwin, London.

Bhabha, Homi K. (1990), ñThe other question, difference, discrimination, and the discourse of colonialismòen Russell Ferguson, Martha Gever, Thinh Minhha y Comell West (eds.), Out There, Marginalization and Contemporary Cultures, Mit Press, New York.

Boccara, Guillaume (2007), r̃Chile y śusôpueblos indígenas. De la invisibilización-subalternización del indígena a la nueva conquista espiritual de las fronteras del capitalismo globalizado (siglos XIX-XXI)òen Sociedades en movimiento. Los Pueblos indígenas de América Latina en el siglo XIX, IEHS, Tandil.

Braidotti, Rosi (1994), Nomadics subjects, University Press, Columbia.

Bustos, R. M. (1983), íFactores potenciales de desarrollo o estancamiento en una zona árida, Departamento de Lavalle, Mendozaò Deserta, núm. 7 , Mendoza, Argentina.

Cahiza, Pablo A. (2000), Ĩnvestigaciones arqueológicas e históricas del área lacustre de Guanacache, Lavalle, Mendozaò Cuaderno del Centro de Graduados, núm. 5, Mendoza, Argentina.

Cajigas-Rotundo, Juan Camilo (2007), r̃a biocolonialidad del poder. Amazonia, biodiversidad y ecocapitalismoò en Grosfoguel, Ramón y Santiago Castro-Gomez (eds.), El giro decolonial. Reflexiones para una 
diversidad epistémica más allá del capitalismo global, Siglo XXI, Bogotá. Canals Frau, Salvador (1946), r̃Etnología de los Huarpes. Una síntesisò Anales del Instituto de Etnografía Americana, vol. 3, núm. 9, Argentina. Carrera Becerra, Gabriel, E. Franky Calvo, Dany Mahecha Rubio (1999), Los n)kak: nómadas de la Amazonia colombiana, Universidad Nacional de Colombia, Colombia.

Casciarri, Barbara (2009), íBetween market logic and comunal practices: pastoral nomad groups and globalization in contemporary Sudan (case studies from central and western Sudan)à Nomadic peoples, v. 13, n. 1, White Horse Press, UK.

Castro-Gómez, Sergio (2005), La Hybris del punto cero. Ciencia, raza e ilustración en la Nueva Granada (1750-1816), Pontificia Universidad Javeriana, Bogotá.

Chiavazza, Horacio (2001), Las Antiguas poblaciones de las arenas. Arqueología en las tierras áridas del noreste mendocino, Ediciones Culturales de Mendoza-Serie Bienes Patrimoniales Mendoza, Mendoza. Chiavazza, Horacio (2009), ñGarganta seca y arena en las botas: prospectando antecedentes arqueológicos de las tierras áridas del noreste mendocino (Centro Oeste Argentino)ò, Arqueología Iberoamericana, núm. 1.

Chiavazza, Horacio (2010), ñOcupaciones en antiguos ambientes de humedal de las tierras bajas del norte de Mendoza: sitio Tulumaya (PA70)ò Intersecciones en Antropología, núm. 11, Argentina.

Chiavazza, Horacio (2013), ñôo tan simplesô pesca y horticultura entre grupos originarios del norte de Mendozaò Comechingonia virtual, Revista Electrónica de Arqueología, núm. 1, Argentina.

Chiavazza, Horacio (2015), ĩPescadores y horticultores ceramistas del valle de Mendozaò Xama. Serie Monografías, núm. 5, Argentina.

Dahl, Gudrun, Anders Hjort (1980), ז̂́Some thoughts on the anthropological study of pastoralismò Nomadic Peoples, n. 5, White Horse Press, uk. Deleuze, Gilles, Felix Guattari (1980), Mille plateaux (capitalisme y schizophénie), Minuit, Paris,

Derrida, Jacques (1996), Le monoliguisme de lëautre, Galilée, Paris. de Weijer, F. (2002), ĩPastoralist vulnerability studyò Afghanistan Food Security Unit, World Food Programme, en ftp.fao.org/country/afghanistan/ kuchi.pdf, Acceso el 31 de octubre de 2007. 
Engebrigtsen, Ada Ingrid (2017), îey figure of mobility: the nomadò Social Anthropology/Anthropologie Sociale, v. 25, n. 1.

Escolar, Diego (2007), Los dones étnicos de la nación. Identidades huarpe y modos de producción de soberanía en Argentina, Prometeo, Buenos Aires.

Ferguson, James, Akhil Gupta (2002), ז̂spatializing states: toward an ethnography of neoliberal governmentalityòEn American Ethnologist, v. 29, n. 4.

Foucault, Michel (1976), ñl faut défendre la sociétéò Dits et Ecrits, Tomo ॥, texto $n^{\circ} 187$, Seuil, Gallimard, España.

Foucault, Michel (1976), íBio-histoire et bio-politiqueò En Le Monde, Dits et Ecrits, tomo III, texto 179, Francia.

Foucault, Michel (2004[1977-1978]), Sécurité, territoire, population. Curso en el Collègue de France, Seuil/Gallimard, Paris.

Franky Calvo, E. y Dany Mahecha Rubio (2011), Los n)kak. El último pueblo de tradición nómada contactado oficialmente en Colombia. Informe IWGIA 11. Universidad Nacional de Colombia, Colombia.

García, Alejandro (2004), Tras las huellas de la identidad huarpe. Un aporte desde la arqueología, la antropología y la historia, Facultad de Filosofía y Letras, Universidad Nacional de Cuyo, Mendoza.

Gasco, Valeria Alejandra, Víctor Durán, Laura Piazze, Miguel Giardina, Guillermo Campos (2015), Ñeranadas sin frontera. Etnografía de pastores en el Centro-Oeste argentinoò Revista del Museo de Antropología, vol. 8, núm. 2, IDACOR-CONICET / Facultad de Filosofía y Humanidades, Universidad Nacional de Córdoba, Argentina.

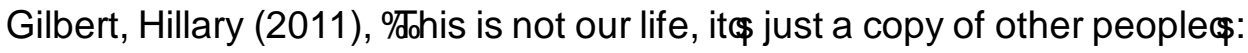
Bedu and the Price of ólevelopmentôn South Sinaiò Nomadic Peoples, v. 15, n. 2, White Horse Press, UK.

Gilbert, Jérémie (2012), 亿̃and rights and nomadic peoples: using international law at the local levelò Nomadic Peoples, v. 16, n. 2, White Horse Press, UK.

Gilbert, Jérémie (2007), Ñomadic territories: a human rights approach to nomadic peoples land rightsò Human Rights Law Review, v. 7, n. 4, Oxford University Press, UK.

Göbel, Barbara (2002), ña arquitectura del pastoreo: uso del espacio y sistema de asentamientos en la Puna de Atacama (Susques)ò Estudios Atacameños, núm. 23, Universidad Católica del Norte, Chile. 
Hevilla, María Cristina y Matías Molina (2010), ñTrashumancia y nuevas movilidades en la frontera argentino-chilena de Los Andes Centralesò Revista Transporte y Territorio, núm. 3, uBA, Argentina.

Katzer, Leticia (2004), ñ La comunidad gitana en la ciudad de La Plata y sus alrededores. Apropiaciones y des-apropiaciones de la otredadò Noticias de Antropología y Arqueología, Naya Revista Virtual, Buenos Aires. Disponible en Jornadas Naya http://www.equiponaya.com.ar

Katzer, Leticia (2005), r̃Comunidad e identidad desde la espectrología. Un saludo al naufragio gitanoò Ponencia presentada en el I Congreso Latinoamericano de Antropología. Realizado desde el 11 al 15 de julio de 2005 en la Facultad de Humanidades y Artes de la Universidad Nacional de Rosario, Asociación Latinoamericana de Antropología.

Katzer, Leticia (2009), ñTierras indígenas, demarcaciones territoriales y gubernamentalización. El caso Huarpe, Provincia de Mendozaò Avá. Revista de Antropología, núm. 16, Universidad Nacional de Misiones, Argentina.

Katzer, Leticia (2013), r̃Procesos identitarios, đ́ampos familiaresôy nomadismoò Polis, núm. 34, Universidad de Los Lagos, Chile, disponible en http://polis.revues.org/8813DOl10.4000/polis.8813

Katzer, Leticia (2016), ñiferencia-como-colonia, gubernamentalidad/ biopolítica y vivir bien (en común): derivaciones decoloniales del pensamiento de Derrida, Foucault y la crítica poscolonialò Tabula Rasa, núm. 25, Bogotá, Colombia.

Katzer, Leticia (2015), r̂árgenes de la etnicidad. De fantasmas, espectros y nomadológica indígenaò Tabula Rasa, núm. 22, Bogotá, Colombia. Katzer, Leticia (2018a), íEspectrografías nómades del ólesiertoôlel NE de Mendoza, Rca Argentinaò Plural, núm. 2, Asociación Latinoamericana de Antropología, Argentina.

Katzer, Leticia (2018b), Hacia una antropología de la biopolítica, Editorial de la Universidad del Aconcagua, Mendoza.

Katzer, Leticia et al. (2017), íBio-historia del nomadismo y de la producción territorial del NE de Mendoza. Lectura interdisciplinaria desde la ecología, la arqueología y la etnografíaò Relaciones de la Sociedad Argentina de Antropología, tomo 42, núm. 2, Universidad Nacional de La Plata.

Lacoste, Pablo (1998), Lavalle, La Paz y Santa Rosa. Historia y Perspectivas, Diario Uno, Mendoza. 
Lander, Edgardo (2000), r̃̃iencias sociales: saberes coloniales y eurocéntricosòen Lander, Edgardo (comp), La colonialidad del saber: eurocentrismo y ciencias sociales. Perspectivas latinoamericanas, CLACSO, Buenos Aires.

Latour, Bruno (2007 [1991]), Nunca fuimos modernos. Ensayo de antropología simétrica, Siglo xxI, Buenos Aires.

Maino, Valeria (2015), Trashumancia en el valle del Choapa, Los Pelambres,

Origo ediciones, Chile.

Manzur, Gregorio (2007), Guanacache, las tierras de la sed, Fundación Marañón, Mendoza.

Marchi, Paolo (2010), ñThe right to health of nomadic groupsò Nomadic Peoples, v. 14, n.1, White Horse Press, uk.

Medina, Matías E. (2015), r̃́asas-pozo, agujeros de postes y movilidad residencial en el periodo Prehispánico tardío de las Sierras de Córdoba, Argentinaòen Salazar, J. Condiciones de posibilidad de la reproducción social en sociedades prehispánicas y coloniales tempranas en las Sierras Pampeanas (República Argentina), Centro de Estudios Históricos Prof. Carlos A. Segreti, Córdoba.

Metreaux, Alfred (1937[1929]), r̃ Contribución a la etnografía y arqueología de la provincia de Mendozaò Revista de la Junta de Estudios Históricos de Mendoza, Tomo VI, núm. 15, Argentina.

Micheli, Catalina (1983), Los Huarpes protohistóricos, Universidad Nacional de San Juan, San Juan.

Montaña, Elma et al. (2005), ños Espacios Invisibles. Subordinación, Marginalidad y Exclusión de los Territorios no irrigados en las Tierras Secas de Mendoza, Argentinaò Región y Sociedad, vol. 17, núm. 32, Hermosillo, México.

Molina Otarola, Rafael (2014), r̃ ordillera de Atacama. Movilidad, frontera y articulaciones collas-atacameñasòen Núñez, Andrés, Rafael Sánchez, Federico Arenas (eds.), Fronteras en movimiento e imaginarios geográficos. La cordillera de los andes como espacialidad sociocultural, Pontificia Universidad Católica de Chile, Chile.

Núñez, Andrés, Raúl Molina, Enrique Aliste, Álvaro Bello (2016), ĩsilencios geográficos en Patagonia-Aysén: territorio, nomadismo y perspectivas para re-pensar los márgenes de la nación en el siglo xıxò Magallania, v. 44, núm. 2, Chile. 
Otaola, Clara, Miguel Ángel Giardina, Matew Fry, Gustavo Neme, Steven Wolverton (2016), ñooarqueología y tafonomía en pastores actuales del sur de Mendozaò Intersecciones en Antropología, núm. 17, Universidad del Centro, Argentina.

Pannunzio de Mulle, María (1976), ñagunas del Rosario. Estudio Preliminar de una población de zona áridaò Anales de Arqueología y Etnología, Argentina, núm. 29.

Parisii, M. (1994), r̃algunos datos de las poblaciones prehispánicas del Norte y Centro Oeste de Mendoza y su relación con la dominación inca del áreaò Xama, núm. 45.

Pastor, Gabriela C. (2005), íPatrimonio, vivienda y agua en el Paisaje del Noreste Mendocino. El agua en Iberoamérica. Uso y gestión del agua en tierras secasò El agua en Iberoamérica, vol. XI, Mendoza.

Pastor, Gabriela y Laura Torres (2010), ñTurismo en territorios periféricos? Algunas reflexiones a propósito de un estudio de caso en el Фesierto de LavalleôA Argentinaò Estudios y perspectivas en turismo, vol. 19, núm. 2, Argentina.

Peeters, Benoit (2013 [2010]), Derrida, FCE, Buenos Aires.

Pels, Peter (1997), ñThe Anthropology of colonialism: culture, History and the Emergence of Western Governmentalityò Annual Review of Anthropology, v. 26, Palo Alto, California.

Prieto, M. (1999), ñAntecedentes huarpes de los pobladores del Noreste de la Provincia de Mendozaò Informe del Instituto de Ciencias Humanas, Sociales y Ambientales, Mendoza.

Rabinow, Paul, Nicolas Rose (2006), íBiopower todayò Biosocieties, n. 1, Springer USA, pp. 195-217.

Restrepo, Eduardo (2004), íBiopolítica y alteridad: Dilemas de la etnización de las Colombias Negrasòen Eduardo Restrepo y Axel Rojas (eds.), Conflicto e (in)visibilidad. Retos en los estudios de la gente negra en Colombia, Popayán, Editorial Universidad del Cauca, Colombia.

Rival, Laura (2006), ñAmazonian Historical Ecologiesò The Journal of the Royal Anthropological Institute, Ethnobiology and the Science of Humankind, v. 12, The Royal Anthropological Institute of Great Britain and Ireland, UK.

Rusconi, C. (1962), Poblaciones pre y poshispánicas de Mendoza, vol. I a Iv. Imprenta Oficial Mendoza, Mendoza. 
Saldi, Leticia (2016), ĩEl Estado-sistema frente a la cuestión indígena. Análisis de los modos de reconocimiento de derechos a la identidad Huarpes, al agua y a tierras comunales en Mendoza (Argentina)ò Universitas Humanisticas, núm. 82, Colombia, en http://www.revistas. javeriana.edu.co/index.php/ univhumanistica/article

Schlee, Günter (2013), ñTerritorializing ethnicity: the imposition of a model of statehood on pastoralists in northern Kenya and southern Ethiopiaò Ethnic and Racial Studies, v. 36, n. 5, Taylor \& Francis, UK.

Schweitzer, Peter P., Robert H Hitchcock, Megan Biesele (eds.) (2000), Hunters and Gatherers in the Modern World: Conflict, Resistance, and Self-Determination, Berghahn Books, New York.

Tapper, Richard (2008), wWho Are the Kuchi? Nomad Self-Identities in Afghanistanò The Journal of the Royal Anthropological Institute, v. 14, n. 1 , The Royal Anthropological Institute of Great Britain and Ireland, UK.

Tomasi, Jorge (2013), rEEspacialidades Pastoriles en las Tierras Altoandinas. Asentamientos y Movilidades en Susques, Puna de Atacama (Jujuy, Argentina)ò Revista de Geografía Norte Grande, vol. 55, Chile.

Triviño, Luis (1977), Antropología del Desierto, Fundación para la Educación, la Ciencia y la Cultura, Buenos Aires.

Velez, Silvina, Natacha P.Chacoff, Claudia M. Camposa (2016), î́Seed predation and removal from feces in a dry ecosystemò Basic and Applied Ecology, n. 17, Journal of the Ecological Society of Germany, Austria and Switzerland.

Vignati, A (1931), r̃ Contribución al conocimiento de la etnografía moderna de las Lagunas de Huanacache. Notas preliminares del Museo de la Plataò T. I, Argentina.

Werry, Margaret (2008), ñTourism, race and the state of nature. On the biopoetics of governmentò Cultural Studies, v. 22, n. 3, Routledge, UK.

Zamorano, M. (1950), ñAcerca de la vivienda natural en la república Argentina y especialmente en Mendozaò Anales de Arqueología y Etnología, Tomo xI, Mendoza. 